\title{
Empirical Analysis of Flow Characteristics in Physical Activity: Evidence from College Students in Shanghai
}

\author{
Maoguo Wu \\ Min Tan
}

SHU-UTS SILC Business School, Shanghai University, China

Doi: 10.19044/esj.2018.v14n13p89 URL:http://dx.doi.org/10.19044/esj.2018.v14n13p89

\begin{abstract}
Chinese college students' physical activity mainly consists of physical activity in physical education (PE) classes and extra-curriculum physical activity. With the improvement of college PE teaching, as well as the decline of college students' physique and the frequent occurrence of psychological problems in college students, more and more Chinese colleges has started promoting students' active participation in physical activity. This is performed as a means of improving the physique and the mental health of college students. Flow is a positive psychological experience that quite often takes place in physical activity. Based on the theory of flow, this paper investigates flow characteristics in physical activity of college students in Shanghai. Contributing to existing literature on flow, this paper focuses on empirically exploring the manifestation of flow characteristics, differences in flow characteristics in different types of sports, and differences in flow characteristics in different grades of college students in Shanghai. The data are collected from questionnaire survey. Questionnaire questions are based on the Flow State Scale of Jackson and Marsh (1994). A preliminary test was carried out to assess the effectiveness of questionnaire questions. According to test results, a minor amendment of questionnaire questions was made to ensure that all questionnaire questions can be effectively understood. 500 questionnaires are handed out, and all were successfully retrieved. Factor analysis is utilized to reduce dimension, i.e., factorizing the answers to 36 questions into 6 variables and in calculating the value of flow. Test results found that the manifestation of flow characteristics in physical activity of college students in Shanghai are "self-experience", "integration of action and awareness", "clear goals and feedback", "lack of self-consciousness", "sense of control", and "time transformation". There are sharp differences between flow characteristics in physical activity of different types of sports. The flow in closed motor skills physical activity is higher than that in open motor skills physical activity. The main differences are manifested through four factors:
\end{abstract}


self-experience, integration of action and awareness, clear goals and feedback, and sense of control. There are also significant differences among flow characteristics of college students in different grades, with freshmen having the highest value of flow. The flow characteristics of students in different grades also differ in terms of different types of sports.

Keywords: Flow, College Students, Closed Motor Skills Physical Activity, Open Motor Skills Physical Activity

\section{Introduction}

In recent years, with the implementation of the National Fitness Program and the thought of "Health First" in schools, exercising (including physical education and extra-curricular physical activity) has become an important aspect of college life. The National Outline of Physical Education Curriculum in Colleges states that the goal of mental health of physical education curriculum is that students consciously experience the pleasure of sports and the feeling of success in sports. This aims to improve their psychological state, overcome psychological barriers, develop positive and optimistic attitudes towards life, and use appropriate methods to adjust their emotion. Thus, physical education in colleges aims to promote the cultivation of positive emotion among students.

$\mathrm{Li}$ (2005) argues that exercising has become a new fashion of life style in colleges. In sports, the flow experience is an ideal experience that unconsciously occurs. This kind of experience is usually achieved when the exerciser is in a state of high concentration, i.e., the exerciser forgets himself and fully gets involved in the exercise, generating a sense of control over the movement process and enjoying the process. Privette and Bundrick (1987) conducted a questionnaire survey on 123 college students and compared activities such as sports, cultural studies, interpersonal relations, and religious activities. Therefore, they found that physical exercise was the main source of flow experience.

College students' lack of exercise has already led to a decline in their physiques. In recent years, Chinese colleges have been continuously strengthening physical fitness tests of college students in order to improve the physique of college students and cultivate their lifelong sports consciousness. Therefore, how to make college students to actively participate in sports so that the effectiveness of sports can be further promoted is particularly important in college education. At the same time, college students belong to a special social group, who face various pressures in their daily life. These pressures include problem of adaptation to the new environment, choosing majors, conflict between ideals and reality, handling interpersonal relations, career planning etc. Thus, the following questions have become major 
concerns for colleges: how to alleviate psychological stress of college students, how to deal with crisis or disorder caused by the above mentioned psychological pressures, how to improve college students' physical and mental health so that they can adapt to the fast developing social environment with a positive and proactive psychological state, and how to prevent physical and mental illnesses.

Pleasant exercising can bring positive emotion such as happiness, peak experience, satisfaction, flow, and optimal psychological state. The flow experience helps to exaggerate these kinds of feelings. In the same way, flow experience also helps increase people's enthusiasm for participating in sports and therefore promotes healthy development of mentality. At present, research on the relationship between sports and psychological effects are mostly focused on the effects of sports in overcoming negative psychological state. However, the reinforcing effect of sports on positive psychology cannot be neglected. Previous research on flow experience mainly focuses on investigation of the flow experience in athlete competition. Relatively, very limited research investigates the flow experience of sports in daily life. In particular, research on the flow experience of college students in sports is still scanty.

Consequently, sports places emphasis on obtaining comfortable feeling, psychological pleasure, and satisfaction. Sports also promote spiritual relaxation. This paper investigates college students in Shanghai and comprehensively explores the characteristics of flow experience in college students' physical activity. It analyzes differences in the flow characteristics of different types of sports and establishes the differences among flow characteristics of college students in different grades.

\section{Related Literature}

\section{The Concept of Flow Experience}

The concept of flow experience was first proposed by Csikszentmihalyi (1975). People show their concentration when participating in activities that are purposeful, such as chess, rock climbing etc. This experience or psychological state is known as the "flow experience". Csikszentmihalyi (1988) further extends the previous definition of flow experience. Consequently, a special kind of mental state emerges when people participate in a task that they are capable of solving. This is seen especially when the task is relatively challenging, when they need to utilize a lot of resources and skills that they already possess, and when they are driven by internal motivation. Furthermore, Csikszentmihalyi (1990) once again revised the definition: "flow experience is a self-targeted experience (act for oneself), and this experience is accompanied by a higher state of experience than usual." When the individual believes that there is a balance between the level of 
challenging activities and their own abilities, and both of them are higher than usual, a flow experience can be created.

Ren, Shi, and Ma (2004) essentially explained the concept of flow experience. It is an important positive emotion, which refers to people's interest in full-participation in a certain activity. It is an emotional experience of investing in this activity. $\mathrm{Xu}$ (2007) states that flow experience is a kind of happy state of mind that people have when they are immersed in a task. It is also called the best experience when individuals engage in activities. Zhu (2008) defined the flow experience as a condition where an individual is fully integrated into his or her own interests and focuses only on the part that he or she is interested in, and loses the perception of other irrelevant things. When people are in a flow experience, they forget about themselves and have no space to deal with other issues in their mind. Self-consciousness disappears and the sense of time gets distorted. Jackson and Marsh (1994) introduced the flow experience into the field of sports psychology and defined it as an optimal state of experience in which athletes devote themselves to a task and create a state of consciousness that induces the best level of performance.

Previous research has examined external manifestation of "flow", "concentration", "best experience", and other features of flow experiences. Thus, flow experience is defined around three aspects: dedication, best experience, and focus on tasks.

\section{Characteristics of Flow Experience}

Jackson and Marsh (1996) confirmed the characteristics of people's flow experience in sports. Horn (1992) summarized the manifestation of flow characteristics as the following:

a. Balance between Challenges and Ability: When people perceive the balance of challenge and their abilities at this time, they can achieve a flow experience (Csikszentmihalyi, 1988). If challenges and abilities are not balanced, it is difficult for people to have a flow experience.

b. Amalgamation of Action and Consciousness: The integration of action and consciousness means that participation is so deep that actions become spontaneous or automated (Csikszentmihalyi, 1990). Jackson (1992) stated that top athletes use words such as "in the best condition" or "I did not think of anything and the action naturally occurred" as descriptions of flow experience.

c. Clear Goals and Feedback: When one has a clear goal, one is more likely to concentrate. In addition, a clear goal makes feedback processing easier. A strong symbiotic relation between goals and feedback creates an order in consciousness, which is at the core of flow experience.

d. Fully Immersed: Csikszentmihalyi (1997) believed that "when the goal is clear, the feedback is relevant, the challenges and abilities are balanced, 
and the attention is organized and full of affection." The full requirements of spiritual energy make a person highly focused on a flow experience.

e. Sense of Control: When a person is in a flow experience, he or she feels completely in control of the situation without fear of losing control.

$f$. Lack of Self-awareness: When athletes are fully engaged in sports, they tend to lose self-awareness, creating a situation in which they care only about themselves in the game and do not care how others think of themselves.

g. Time Shift: In this state, athletes feel that time flies not in the same way with the reality, either faster than usual, or slower than usual.

h. Self-contained Experience: Csikszentmihalyi (1990) described selfdevelopment as a result of flow experience, or an intrinsic reward and experience of enjoyment.

i. Positive Output of Flow Experience: There is a very strong and positive relation between flow experience and positive influence.

\section{Sports and Positive Psychological Effects}

Liang et al. (1994) found that regular participation in sports can improve mental health. Ren (2004) found that college students who regularly participate in sports have better mental health than those who do not exercise regularly. Participating in group sports is more conducive to mental health than participation in individual sports.

Csikszentmihalyi (1984) found that organized sports can bring more positive experience than regular daily sports. In informal movement, sense of control is the strongest, while sense of control is the weakest in physical education class. Nevertheless, skills awareness and organizational performance were the strongest in physical education class.

Privette and Bundrick (1987) investigated 123 college students and compare their flow experience in sports, studies, work, interpersonal interaction, and religious activities. They found out that the flow experience mainly comes from sports. Karageorghis et al. (2000) studied the flow experience of aerobic dancing and found that people tend to feel rejuvenated after flow experience in exercising and long for the next. Therefore, there is a clear positive correlation between flow experience and active participation in sports. This means that the flow experience encourages people to exercise through their active participation in sports.

\section{Characteristics of Flow Experience in Sports}

Regarding research on flow experience of the nine characteristics discussed above, different research objects and different research methods find different manifestation of flow characteristics. Hu et al. (2002) studied the performance of female volleyball players of the highest level in international competitions and found that all scores of the nine characteristics are medium 
or high for athletes of both countries. Besides, there was no difference in the overall level of flow experience. This is in line with the fact that the women's volleyball teams of the two countries are among the world's top 8. Hu et al. (2004) found that the flow experience of athletes in skillful projects mainly reflects through five characteristics: accurate feedback, balance of challenges and abilities, clear goals, high sense of control, and concentration. At the same time, it was found that the level of sports have a significant influence on the flow experience of athletes in terms of types of skills. Liu (2005) found that male soft tennis players are more likely to obtain flow experience than female soft tennis players. High-level college tennis players often have clear goals and full confidence in sports.

Jiang and Sun (2001) stated that there was a high degree of consistency between flow experience and athletes' performance. Li (2008) found out that the main factors affecting the flow experience of baseball players and softball players were the training period and the level of exercise. That is, the longer the training period of athletes and the higher the level of sports, the smoother the flow experience is. The flow experience of the 9 baseball team members, participating in the research, was highly related to the scores achieved in the preliminary screening of the 9th National Games. Sun et al. (2000) found that the significant differences in the effect of training period on the flow experience of athletes were mainly reflected in two factors: "balance of challenges and abilities" and "integration of action and consciousness". However, there was no significant difference in other factors.

Liu (2005) finds that there are seven characteristics of flow experience in badminton: sense of control, pleasure, integration of action and consciousness, clear goals, self-consciousness, and concentration. $\mathrm{Hu}$ (2008) found that there were certain differences between genders in the flow experience. Male athletes experience smoother levels of experience than female athletes. The flow experience of athletes specialized in open motor skilled sport was higher than that of athletes specialized in closed motor skilled sport. The characteristic "sense of control" in women's flow experiences are significantly higher than that of men. This is closely related to women's coordination and flexibility.

Zhou (2008) found that the characteristics of the flow experience of college students in sports are mainly reflected in five aspects: reduced selfconsciousness, clear goals, balance of challenges and abilities, integration of action and consciousness, and pleasant experience. $\mathrm{Hu}$ (2008) found that different content taught in PE class made students have different experiences in sports. The characteristics of flow experience of performance-accurate items in open motor skilled sports include: clear goals, lack of self-awareness, and time shift. The flow experience characteristics in closed motor skilled sports were mainly: balance of challenges and abilities, integration of action 
and consciousness, and sense of control. Applying the flow experience theory to PE teaching practice can enable students to have a flow experience and encourage students to participate in sports more actively.

Previous research on the characteristics of flow experience does not have a consensus classification of dimensions of flow experiences. It lacked a comprehensive, clear, and generalized flow experience definition and factor classification. Most studies use athletes as research objects. Also, little research has been done on the characteristics of flow experience of ordinary college students. At the same time, most research methods are psychometric methods and literature review methods. However, there is little empirical research on this field. The overview of the research design and the method used in this paper can be illustrated by Figure 1 .

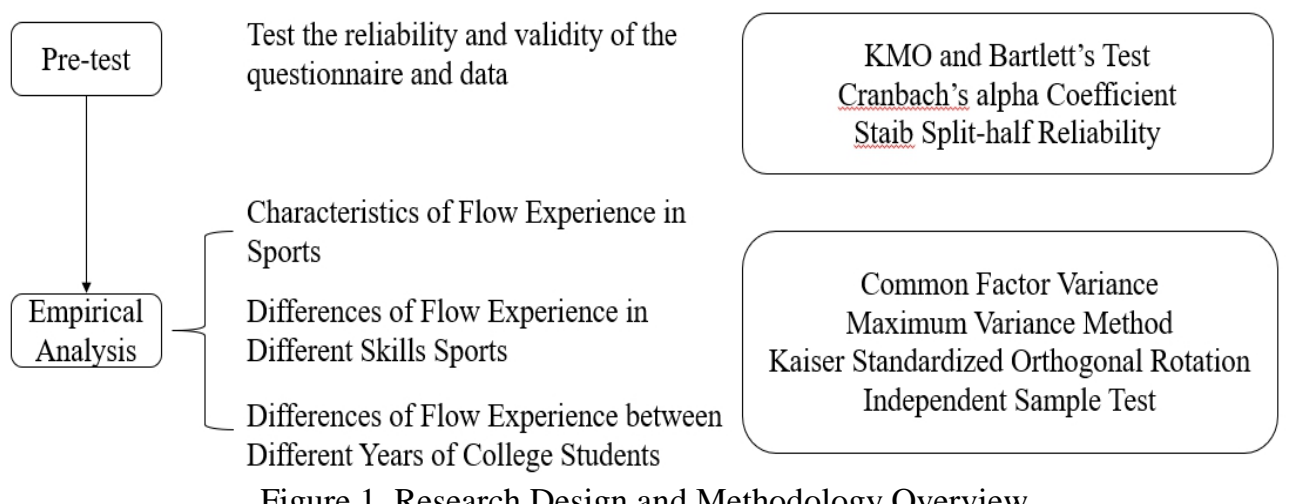

Figure 1. Research Design and Methodology Overview

\section{Preliminary Test}

This paper conducted a survey of 500 college students in Shanghai who are participating in different sports. The physical activities include football, basketball, volleyball, tennis, badminton, table tennis, aerobics, yoga, running, swimming, and fitness. Students in the sample are divided into two sub samples. In order to effectively test the reliability and validity of the scale, 200 students in Shanghai were randomly selected as the preliminary test sample.

The questionnaire was based on "Flow Status Scale" of Jackson and Marsh (1994). The questionnaire mainly reflects personal experience of college students in sports. The test intensity of the scale was divided into 5 subscales, in which 1 denotes "never" and 5 denotes "always". The corresponding score of each item is 1-5 points, with the highest score being 5 and the lowest score being 1. Questions (variables in empirical analysis) of the questionnaire are listed in Table 1. 
Table 1. Flow Status Scale

\begin{tabular}{|c|c|}
\hline $\begin{array}{l}\text { Variable } \\
\text { s }\end{array}$ & Questions \\
\hline V1 & $\begin{array}{c}\text { I was challenged, but I believed my skills would allow me to meet the } \\
\text { challenge. }\end{array}$ \\
\hline $\mathrm{V} 2$ & I made the correct movement without thinking about trying to do so. \\
\hline V3 & I knew clearly what I wanted to do. \\
\hline V4 & It was really clear to me that I was doing well. \\
\hline V5 & My attention was focused entirely on what I was doing. \\
\hline V6 & I felt in total control of what I was doing. \\
\hline V7 & I was not concerned with what others may have been thinking of me. \\
\hline V8 & Time seemed to alter (either slowed down or speeded up). \\
\hline V9 & I really enjoyed the experience. \\
\hline V10 & My abilities matched the high challenge of the situation. \\
\hline V11 & Things just seemed to be happening automatically. \\
\hline V12 & I had a strong sense of what I wanted to do. \\
\hline V13 & I was aware of how well I was performing. \\
\hline V14 & It was no effort to keep my mind on what was happening. \\
\hline V15 & I felt like I could control what I was doing. \\
\hline V16 & I was not worried about my performance during the event. \\
\hline V17 & The way time passed seemed to be different from normal. \\
\hline V18 & I loved the feeling of that performance and want to capture it again. \\
\hline V19 & I felt I was competent enough to meet the high demands of the situation. \\
\hline V20 & I performed automatically. \\
\hline $\mathrm{V} 21$ & I knew what I wanted to achieve. \\
\hline V22 & I had a good idea while I was performing about how well I was doing. \\
\hline $\mathrm{V} 23$ & I had total concentration. \\
\hline V24 & I had a feeling of total control. \\
\hline V25 & I was not concerned with how I was presenting myself. \\
\hline V26 & It felt like time stopped while I was performing. \\
\hline V27 & The experience left me feeling great. \\
\hline V28 & The challenge and my skills were at an equally high level. \\
\hline V29 & I did things spontaneously and automatically without having to think. \\
\hline V30 & My goals were clearly defined. \\
\hline V31 & I could tell by the way I was performing how well I was doing. \\
\hline V32 & I was completely focused on the task at hand. \\
\hline V33 & I felt in total control of my body. \\
\hline V34 & I was not worried about what others may have been thinking of me. \\
\hline V35 & At times, it almost seemed like things were happening in slow motion. \\
\hline V36 & I found the experience extremely rewarding. \\
\hline
\end{tabular}

A preliminary test was conducted in June 2017, and 200 questionnaires were handed out for the preliminary test. First of all, the validity of the questionnaire was tested. The results are shown in Table 2. 
Table 2. KMO and Bartlett's Test

\begin{tabular}{c|c|c}
\hline \multicolumn{2}{c}{ Sampling Sufficient Degree: Kaiser-Meyer-Olkin } & 0.902 \\
\hline \multirow{3}{*}{ Barlett"s Spherical Test } & Approximate chi^2 & 4896.473 \\
& Df & 420 \\
& Sig. & 0.000 \\
\hline
\end{tabular}

The KMO value is 0.902 , which means that the scale is suitable for factor analysis. The common factor variance can be used as a culling basis. If the value is less than 0.2 , the question should be eliminated. Table 3 shows that the common factor variance of all 36 questions in the scale is greater than 0.2. Therefore, there is no need to exclude any questions.

Table 3. Common Factor Variance

\begin{tabular}{ccc|ccc}
\hline Question & $\begin{array}{l}\text { Initial } \\
\text { Value }\end{array}$ & Extraction & Question & $\begin{array}{c}\text { Initial } \\
\text { Value }\end{array}$ & Extraction \\
\hline 1 & 1.000 & 0.629 & 19 & 1.000 & 0.633 \\
2 & 1.000 & 0.724 & 20 & 1.000 & 0.614 \\
3 & 1.000 & 0.542 & 21 & 1.000 & 0.685 \\
4 & 1.000 & 0.563 & 22 & 1.000 & 0.614 \\
5 & 1.000 & 0.614 & 23 & 1.000 & 0.584 \\
6 & 1.000 & 0.608 & 24 & 1.000 & 0.562 \\
7 & 1.000 & 0.582 & 25 & 1.000 & 0.438 \\
8 & 1.000 & 0.712 & 26 & 1.000 & 0.683 \\
9 & 1.000 & 0.608 & 27 & 1.000 & 0.654 \\
10 & 1.000 & 0.576 & 28 & 1.000 & 0.606 \\
11 & 1.000 & 0.458 & 29 & 1.000 & 0.432 \\
12 & 1.000 & 0.595 & 30 & 1.000 & 0.635 \\
13 & 1.000 & 0.547 & 31 & 1.000 & 0.506 \\
14 & 1.000 & 0.438 & 32 & 1.000 & 0.542 \\
15 & 1.000 & 0.548 & 33 & 1.000 & 0.71 \\
16 & 1.000 & 0.632 & 34 & 1.000 & 0.724 \\
17 & 1.000 & 0.659 & 35 & 1.000 & 0.418 \\
18 & 1.000 & 0.532 & 36 & 1.000 & 0.723 \\
\hline
\end{tabular}

Principal component analysis was applied to analyze the data, and 7 factors are selected with the characteristic value greater than 1 as the selection factor. The explanation of the total variance is shown in Table 4. The maximum variance method is used for factor analysis, and the orthogonal rotation method with Kaiser Standardization is applied. The result is shown in Table 5. 
Table 4. Explanation of the Total Variance

\begin{tabular}{cccccccccc}
\hline & \multicolumn{3}{c}{$\begin{array}{c}\text { Initial } \\
\text { Characteristics }\end{array}$} & \multicolumn{3}{c}{$\begin{array}{c}\text { Extracting Square Sum } \\
\text { and Loading }\end{array}$} & \multicolumn{3}{c}{$\begin{array}{c}\text { Rotated Square Sum } \\
\text { and Loading }\end{array}$} \\
\cline { 2 - 10 } & Total & Var\% & Accu.\% & total & Var\% & Accu.\% & total & Var\% & Accu.\% \\
1 & 11.984 & 33.290 & 33.290 & 11.984 & 33.290 & 33.290 & 6.181 & 17.169 & 17.169 \\
2 & 2.584 & 7.179 & 40.468 & 2.584 & 7.179 & 40.468 & 4.853 & 13.481 & 30.650 \\
3 & 1.809 & 5.024 & 45.492 & 1.809 & 5.024 & 45.492 & 2.844 & 7.900 & 38.550 \\
4 & 1.540 & 4.278 & 49.771 & 1.540 & 4.278 & 49.771 & 2.332 & 6.477 & 45.027 \\
5 & 1.223 & 3.397 & 53.167 & 1.223 & 3.397 & 53.167 & 2.190 & 6.082 & 51.109 \\
6 & 1.116 & 3.100 & 56.267 & 1.116 & 3.100 & 56.267 & 1.654 & 4.595 & 55.703 \\
7 & 1.038 & 2.884 & 59.151 & 1.038 & 2.884 & 59.151 & 1.241 & 3.448 & 59.151 \\
\hline
\end{tabular}

Table 5. Rotation Component Matrix

\begin{tabular}{|c|c|c|c|c|c|c|c|}
\hline \multicolumn{8}{|c|}{ Components } \\
\hline & 1 & 2 & 3 & 4 & 5 & 6 & 7 \\
\hline V6 & 0.725 & 0.236 & 0.141 & 0.049 & 0.071 & -0.017 & 0.081 \\
\hline V28 & 0.719 & 0.128 & 0.049 & 0.248 & -0.096 & 0.094 & 0.021 \\
\hline V15 & 0.672 & 0.105 & 0.175 & 0.224 & 0.085 & 0.008 & -0.076 \\
\hline V31 & 0.627 & 0.238 & 0.082 & 0.157 & 0.082 & 0.187 & 0.003 \\
\hline V33 & 0.622 & 0.153 & 0.084 & 0.325 & 0.132 & 0.104 & 0.092 \\
\hline V3 & 0.615 & 0.167 & 0.041 & -0.136 & 0.291 & 0.049 & 0.113 \\
\hline V4 & 0.614 & 0.196 & 0.122 & -0.187 & 0.272 & 0.084 & 0.068 \\
\hline V24 & 0.612 & 0.354 & 0.058 & 0.142 & 0.171 & 0.106 & -0.031 \\
\hline V10 & 0.592 & 0.281 & 0.043 & 0.317 & 0.141 & -0.052 & 0.166 \\
\hline V13 & 0.574 & 0.298 & 0.096 & 0.286 & 0.121 & 0.022 & -0.158 \\
\hline V1 & 0.564 & 0.401 & -0.051 & -0.094 & -0.065 & -0.033 & 0.442 \\
\hline V30 & 0.546 & 0.192 & 0.073 & 0.062 & 0.531 & 0.103 & -0.064 \\
\hline V12 & 0.528 & 0.353 & 0.131 & 0.124 & 0.338 & 0.154 & -0.092 \\
\hline V36 & 0.278 & 0.764 & 0.081 & 0.178 & 0.086 & 0.098 & 0.012 \\
\hline V27 & 0.284 & 0.743 & 0.082 & 0.116 & 0.023 & 0.136 & -0.039 \\
\hline V26 & 0.138 & 0.687 & 0.082 & 0.193 & 0.021 & 0.304 & -0.027 \\
\hline V9 & 0.327 & 0.685 & 0.081 & 0.145 & 0.027 & -0.081 & -0.076 \\
\hline V5 & 0.205 & 0.603 & 0.165 & -0.238 & 0.242 & 0.038 & 0.271 \\
\hline V23 & 0.252 & 0.574 & 0.196 & -0.042 & 0.385 & 0.066 & 0.093 \\
\hline V32 & 0.352 & 0.524 & 0.142 & 0.164 & 0.268 & 0.144 & 0.152 \\
\hline V18 & 0.204 & 0.507 & 0.086 & 0.422 & 0.188 & 0.146 & 0.056 \\
\hline V19 & 0.413 & 0.492 & 0.098 & 0.416 & 0.182 & 0.027 & 0.103 \\
\hline V34 & 0.231 & 0.088 & 0.794 & 0.012 & -0.004 & 0.039 & 0.097 \\
\hline V16 & 0.065 & 0.072 & 0.774 & 0.143 & 0.118 & 0.062 & -0.051 \\
\hline V7 & -0.037 & 0.061 & 0.694 & 0.069 & 0.233 & 0.019 & 0.161 \\
\hline V35 & 0.171 & 0.164 & 0.537 & 0.192 & -0.095 & 0.110 & -0.148 \\
\hline $\mathrm{V} 25$ & 0.102 & 0.104 & 0.480 & 0.202 & -0.360 & 0.158 & -0.002 \\
\hline V20 & 0.202 & 0.093 & 0.372 & 0.647 & 0.029 & -0.056 & 0.108 \\
\hline V29 & 0.302 & 0.171 & 0.142 & 0.513 & -0.114 & 0.124 & 0.105 \\
\hline V11 & 0.197 & 0.364 & 0.193 & 0.448 & 0.216 & 0.034 & 0.072 \\
\hline V14 & 0.027 & 0.141 & 0.324 & 0.393 & 0.118 & 0.282 & 0.228 \\
\hline V21 & 0.374 & 0.155 & 0.129 & 0.084 & 0.701 & 0.115 & -0.072 \\
\hline V22 & 0.227 & 0.405 & -0.028 & 0.148 & 0.608 & 0.103 & 0.028 \\
\hline V8 & 0.114 & 0.104 & 0.011 & -0.014 & 0.044 & 0.822 & 0.075 \\
\hline V17 & 0.108 & 0.212 & 0.204 & 0.124 & 0.118 & 0.720 & -0.022 \\
\hline V2 & 0.044 & 0.004 & 0.075 & 0.283 & -0.038 & 0.078 & 0.818 \\
\hline
\end{tabular}


From rotated matrix table, it can be seen that the $7^{\text {th }}$ factor contains only one variable. It cannot show the meaning of common factor. As a result, this factor was removed. Therefore, a total of 6 factors are extracted from the scale analysis. According to the characteristic of each factor, the 6 factors are named as sense of control (SOC), self-contained experience (SCE), lack of self-consciousness (LOSC), integration of action and consciousness (AACI), clear goal and feedback (CGAF), and time shift (TT). Table 6 shows the corresponding questions (variables), eigenvalues, and contribution (in percentage) of each factor.

Table 6. Flow Experience Characteristic Factors

\begin{tabular}{|c|c|c|c|c|c|c|}
\hline & \multicolumn{6}{|c|}{ Factors } \\
\hline & SOC & SCE & LOSC & AACI & CGAF & TT \\
\hline & V6、 & & & & & \\
\hline & V28、 & & & & & \\
\hline & V15、 & V36、 & & & & \\
\hline & V31、 & V27、 & & & & \\
\hline & V33、 & V26、 & V34、 & & & \\
\hline & V3、 & V9, & V16, & V20、 & & \\
\hline & V4、 & V5, & V7、 & $\sqrt{29}$. & V21、 & $\begin{array}{l}\text { V8, } \\
\text { V17 }\end{array}$ \\
\hline & V24、 & V23、 & V35、 & V14 & & \\
\hline & V10、 & V32、 & V25 & & & \\
\hline & V13、 & V18、 & & & & \\
\hline & V1、 & V19 & & & & \\
\hline & V30、 & & & & & \\
\hline & V12 & & & & & \\
\hline No. & 13 & 9 & 5 & 4 & 2 & 2 \\
\hline Characteristic & 6.181 & 4.853 & 2.844 & 2.332 & 2.190 & 1.654 \\
\hline Contribution (\%) & 17.169 & 13.481 & 7.900 & 6.477 & 6.082 & 4.594 \\
\hline $\begin{array}{c}\text { Accu. Contribution } \\
(\%)\end{array}$ & 17.169 & 30.650 & 38.550 & 45.027 & 51.109 & 55.703 \\
\hline
\end{tabular}

This paper uses Cronbach's alpha coefficient to test the reliability of data. The results are shown in Table 7.

Table 7. Characteristics of Flow Experience and its Credibility Statistics at All Levels

\begin{tabular}{cccccccc}
\hline & \multicolumn{7}{c}{ Factors } \\
\cline { 2 - 7 } & SOC & SCE & LOSC & AACI & CGAF & TT & Whole \\
\hline No. & 13 & 9 & 5 & 4 & 2 & 2 & 35 \\
\hline A & 0.911 & .895 & 0.741 & 0.668 & 0.724 & 0.602 & 0.939 \\
\hline $\begin{array}{c}\text { Staib Split-Half } \\
\text { Reliability }\end{array}$ & 0.892 & 0.872 & 0.638 & 0.672 & 0.728 & 0.602 & 0.928 \\
\hline
\end{tabular}


The alpha coefficients at all levels are greater than 0.6 of the critical value of general significance test, and there is no need to modify the question at any level. The alpha coefficient of internal consistency test is 0.939 , and the Staib split-half reliability is 0.928 . However, this shows that the questionnaire has high internal consistency. The results of the preliminary test confirm that the questionnaire has high reliability and validity. Therefore, it can be used for the following test.

\section{Empirical Analysis}

\section{Characteristics of Flow Experience in Sports}

In July 2017, a total of 500 questionnaires were handed out, all of which were retrieved without any invalid questionnaires. Among the total sample, there are 168 students from year one, accounting for 33.6\%; 122 from year two, accounting for $24.4 \%$; 114 from year three, accounting for $22.8 \%$; 96 from year four, accounting for $19.2 \%$. There are 382 students participating in open motor skills physical activities (soccer, basketball, volleyball, tennis, badminton, table tennis), accounting for $76.4 \%$ of the total sample. In addition, 118 students was participating in closed motor skills physical activity (aerobics, yoga, running, swimming and fitness), accounting for $23.6 \%$.

Factor analysis shows that the characteristics of the flow experience in sports mainly include 6 factors, which are self-contained experience, integration of action and consciousness, clear goal and feedback, lack of selfconsciousness, sense of control, and time shift. Table 8 provides detailed explanation of the total variance.

Table 8. Explanation of the Total Variance

\begin{tabular}{cccc|ccc|ccc}
\hline & \multicolumn{2}{c|}{ Initial Characteristics } & \multicolumn{3}{c|}{$\begin{array}{c}\text { Extracting Square } \\
\text { Sum and Loading }\end{array}$} & \multicolumn{3}{c}{$\begin{array}{c}\text { Rotated Square } \\
\text { Sum and Loading }\end{array}$} \\
\cline { 2 - 10 } & Total & Var\% & Accu.\% & Total & Var\% & Accu.\% & Total & Var\% & Accu.\% \\
\hline 1 & 12.163 & 34.750 & 34.750 & 12.163 & 34.750 & 34.750 & 4.487 & 12.819 & 12.819 \\
\hline 2 & 2.167 & 6.190 & 40.941 & 2.167 & 6.190 & 40.941 & 4.034 & 11.526 & 24.345 \\
\hline 3 & 1.673 & 4.780 & 45.720 & 1.673 & 4.780 & 45.720 & 3.712 & 10.606 & 34.951 \\
\hline 4 & 1.332 & 3.806 & 49.526 & 1.332 & 3.806 & 49.526 & 2.868 & 8.194 & 43.145 \\
\hline 5 & 1.167 & 3.334 & 52.860 & 1.167 & 3.334 & 52.860 & 2.732 & 7.805 & 50.950 \\
\hline 6 & 1.058 & 3.022 & 55.882 & 1.058 & 3.022 & 55.882 & 1.726 & 4.932 & 55.882 \\
\hline
\end{tabular}

Subsequently, 6 factors are extracted by the maximum variance method. The rotation component matrix is shown in Table 9. 
Table 9. Rotation Component Matrix

\begin{tabular}{|c|c|c|c|c|c|c|}
\hline \multicolumn{7}{|c|}{ Factors } \\
\hline & 1 & 2 & 3 & 4 & 5 & 6 \\
\hline V27 & 0.742 & 0.187 & 0.159 & 0.114 & 0.175 & 0.119 \\
\hline V36 & 0.717 & 0.177 & 0.207 & 0.085 & 0.196 & 0.089 \\
\hline V9 & 0.649 & 0.426 & 0.160 & 0.070 & 0.004 & 0.062 \\
\hline V26 & 0.621 & 0.120 & 0.032 & 0.090 & 0.261 & 0.392 \\
\hline V23 & 0.591 & 0.082 & 0.385 & 0.203 & 0.188 & -0.022 \\
\hline V32 & 0.575 & 0.095 & 0.369 & 0.170 & 0.336 & -0.031 \\
\hline V18 & 0.548 & 0.378 & 0.159 & 0.137 & 0.144 & 0.245 \\
\hline V5 & 0.516 & 0.164 & 0.457 & 0.156 & -0.117 & 0.010 \\
\hline V22 & 0.443 & 0.208 & 0.437 & 0.067 & 0.082 & 0.132 \\
\hline V10 & 0.270 & 0.652 & 0.190 & 0.020 & 0.249 & 0.029 \\
\hline V13 & 0.238 & 0.611 & 0.281 & 0.118 & 0.276 & 0.009 \\
\hline V15 & 0.078 & 0.561 & 0.0258 & 0.174 & 0.322 & 0.022 \\
\hline V6 & 0.130 & 0.557 & 0.434 & 0.104 & 0.170 & -0.016 \\
\hline V11 & 0.275 & 0.513 & 0.065 & 0.194 & 0.068 & 0.139 \\
\hline V20 & 0.149 & 0.463 & 0.001 & 0.397 & 0.351 & 0.039 \\
\hline V19 & 0.435 & 0.462 & 0.225 & 0.133 & 0.200 & 0.081 \\
\hline V14 & 0.022 & 0.439 & 0.006 & 0.431 & 0.040 & 0.243 \\
\hline $\mathrm{V} 1$ & 0.220 & 0.432 & 0.322 & 0.010 & -0.045 & 0.091 \\
\hline V3 & 0.174 & 0.222 & 0.664 & 0.049 & 0.028 & 0.096 \\
\hline V21 & 0.210 & 0.146 & 0.660 & 0.148 & 0.213 & 0.173 \\
\hline V30 & 0.232 & 0.068 & 0.646 & 0.075 & 0.376 & 0.121 \\
\hline V4 & 0.184 & 0.382 & 0.570 & 0.062 & 0.084 & 0.000 \\
\hline V12 & 0.307 & 0.385 & 0.462 & 0.172 & 0.152 & 0.158 \\
\hline V24 & 0.372 & 0.372 & 0.399 & 0.115 & 0.301 & -0.011 \\
\hline V16 & 0.082 & 0.153 & 0.129 & 0.783 & 0.041 & 0.068 \\
\hline V34 & 0.138 & 0.104 & 0.146 & 0.756 & 0.208 & -0.022 \\
\hline V7 & 0.154 & 0.046 & 0.236 & 0.716 & -0.033 & 0.039 \\
\hline V25 & 0.089 & 0.112 & -0.176 & 0.490 & 0.340 & 0.136 \\
\hline V31 & 0.198 & 0.229 & 0.325 & 0.059 & 0.606 & 0.008 \\
\hline V33 & 0.279 & 0.330 & 0.275 & 0.093 & 0.548 & -0.041 \\
\hline V28 & 0.113 & 0.470 & 0.206 & 0.008 & 0.545 & -.041 \\
\hline V29 & 0.142 & 0.304 & 0.071 & 0.230 & 0.523 & 0.179 \\
\hline V35 & 0.209 & -0.004 & 0.012 & 0.396 & 0.496 & 0.189 \\
\hline V8 & 0.114 & 0.026 & 0.157 & 0.027 & 0.062 & 0.798 \\
\hline V17 & 0.156 & 0.131 & 0.097 & 0.166 & 0.064 & 0.748 \\
\hline
\end{tabular}

The corresponding questions, eigenvalues, and contribution of each factor are shown in Table 10. 
Table 10. Flow Experience Characteristic Factors

\begin{tabular}{ccccccc}
\hline & \multicolumn{6}{c}{ Factors } \\
\cline { 2 - 7 } & SCE & AACI & CGAF & LOSC & SOC & TT \\
\cline { 2 - 7 } & V27、 & V10、 & & & & \\
& V36、 & V13、 & V3、 & & & \\
& V9、 & V15、 & V21、 & V16、 & V31、 & \\
& V26、 & V6、 & V30、 & V34、 & V28、 & V8、 \\
& V23、 & V11、 & V4、 & V7、 & V29、 & V17 \\
& V32、 & V20、 & V12、 & V25 & V35 & \\
& V18、 & V19、 & V24 & & & \\
No. & V5、 & V14、 & & & & \\
Characteristic & 9 & 9 & 6 & 4 & 5 & 2 \\
Contribution (\%) & 12.586 & 3.409 & 3.974 & 2.798 & 2.966 & 1.723 \\
Accu. Contribution (\%) & 12.740 & 9.469 & 11.039 & 7.773 & 8.238 & 4.785 \\
& & & & & & \\
\hline
\end{tabular}

\section{Differences of Flow Experience in Different Types of Sports}

The comparison of the characteristics of the flow experience of college students in open and closed motor skills physical activities shows that the average score 132.648 of flow experience in closed motor skills is significantly higher than that in open motor skills with the average score of 118.463. The standard deviation of the flow experience in closed motor skills is also higher than that in open motor skills, indicating that the total score of flow experience is more dispersed in closed motor skills. Detailed results are shown in Table 11.

Table 11. Mean and Standard Deviation of Flow Experience in Different Skills Sports

\begin{tabular}{cccc}
\hline Skill Type & Observations & Average & Standard Deviation \\
\hline Open & 382 & 118.463 & 17.486 \\
Locked & 118 & 132.648 & 19.428 \\
Whole & 500 & 121.811 & 18.583 \\
\hline
\end{tabular}

The independent sample t-test was carried out with the score of the flow experience characteristic values. The $F$ value of the Levene's test with equal variance is less than the critical value $(\mathrm{F}=0.288, \mathrm{P}=0.598>0.05)$, which indicates that the variance of the two groups of samples is different. The degree of freedom is 498 , and $\mathrm{t}=-5.437, \mathrm{P}=0.000<0.01$, which is significant at $1 \%$ significance level. The results are shown in Table 12 . 
Table 12. Independent Sample Test

\begin{tabular}{|c|c|c|c|c|c|c|c|c|}
\hline \multicolumn{4}{|c|}{ Variance Levene's Test } & \multicolumn{5}{|c|}{ Mean T-Test } \\
\hline \multirow{3}{*}{$\begin{array}{l}\text { Total } \\
\text { Score }\end{array}$} & & $\mathrm{F}$ & Sig. & $\mathrm{T}$ & Df & $\begin{array}{l}\text { Sig. } \\
\text { (Two- } \\
\text { Sided) }\end{array}$ & $\begin{array}{c}\text { Mean } \\
\text { Difference }\end{array}$ & $\begin{array}{c}\text { Standard } \\
\text { Error }\end{array}$ \\
\hline & $\begin{array}{c}\text { Equal } \\
\text { Variance }\end{array}$ & \multirow{2}{*}{0.288} & \multirow{2}{*}{0.598} & $\begin{array}{c}- \\
5.437 \\
\end{array}$ & 498 & 0.000 & -5.640 & 1.102 \\
\hline & $\begin{array}{l}\text { Unequal } \\
\text { Variance }\end{array}$ & & & $\begin{array}{c}- \\
5.435 \\
\end{array}$ & 498 & 0.000 & -5.640 & 1.102 \\
\hline
\end{tabular}

The main reason for the more significant flow experience in closed motor skills is that the majority of students' participation in sports aims to lose weight, shape good physical appearance, and improve external image. Compared with open motor skills, college students prefer closed motor skills. Closed motor skills physical activities require small amount of exercise and low technical difficulty. Generally speaking, they are easy to grasp. The teaching method of closed motor skills physical activities is demonstration, which adopts symmetrical design and simple action. Yoga and aerobics have music accompany, which stimulates the enthusiasm of college students and makes them enjoy pleasant experience in sports.

The independent sample t-test is conducted to test why the level of flow experience in closed motor skills sports is higher than that of open motor skills sports. This is achieved by taking the 6 factors of flow experience as the test variables and using the skill type as the grouping variable to analyze the difference of the flow experience characteristics of college students in open motor skills and closed motor skills. The mean and standard deviation of characteristic factors of different skill types are shown in Table 13.

Table 13. Mean Values and Standard Deviations of Factors for Different Skill Types

\begin{tabular}{cccccc}
\hline \multirow{2}{*}{ Skills Type } & Observation & Mean & $\begin{array}{c}\text { Standard } \\
\text { Deviation }\end{array}$ & $\begin{array}{c}\text { Mean } \\
\text { Standard } \\
\text { Error }\end{array}$ \\
\hline \multirow{2}{*}{ SCE } & Open & 382 & 32.180 & 5.631 & 0.231 \\
\cline { 2 - 6 } & Closed & 118 & 33.629 & 5.537 & 0.229 \\
\hline \multirow{2}{*}{ AACI } & Open & 382 & 28.157 & 4.957 & 0.204 \\
\cline { 2 - 6 } & Closed & 118 & 30.094 & 5.220 & 0.216 \\
\hline \multirow{2}{*}{ CGAF } & Open & 382 & 20.471 & 3.683 & 0.151 \\
\cline { 2 - 6 } & Closed & 118 & 21.571 & 3.649 & 0.151 \\
\hline \multirow{2}{*}{ LOSC } & Open & 382 & 12.403 & 2.710 & 0.111 \\
\cline { 2 - 6 } & Closed & 118 & 12.631 & 2.805 & 0.116 \\
\hline \multirow{2}{*}{ SOC } & Open & 382 & 14.973 & 2.968 & 0.122 \\
\cline { 2 - 6 } & Closed & 118 & 15.928 & 3.022 & 0.125 \\
\hline \multirow{2}{*}{ TT } & Open & 382 & 7.042 & 1.4612 & 0.060 \\
\cline { 2 - 6 } & Closed & 118 & 7.162 & 1.4593 & 0.060 \\
\hline
\end{tabular}

Table 13 shows that the 6 factors of flow experience characteristics in closed motor skills sports are all higher than those in open motor skills sports. 
T-tests are performed on 6 characteristics of flow experience in open motor skills and closed motor skills. The results are shown in Table 14.

Table 14. Independent Sample Test

\begin{tabular}{|c|c|c|c|c|c|c|c|}
\hline & & \multicolumn{2}{|c|}{$\begin{array}{c}\text { Variance Levene's } \\
\text { Test }\end{array}$} & \multicolumn{4}{|c|}{ Mean T-Test } \\
\hline & & $\mathrm{F}$ & Sig. & $\mathrm{t}$ & Df & $\begin{array}{l}\text { Sig. (2- } \\
\text { Sided) }\end{array}$ & $\begin{array}{c}\text { Mean } \\
\text { Difference }\end{array}$ \\
\hline \multirow{2}{*}{ SCE } & $\begin{array}{c}\text { Equal } \\
\text { Variance }\end{array}$ & \multirow{2}{*}{0.293} & \multirow{2}{*}{0.589} & -4.452 & 498 & 0.000 & -1.449 \\
\hline & $\begin{array}{c}\text { Unequ. } \\
\text { Variance }\end{array}$ & & & -4.452 & 498 & 0.000 & -1.449 \\
\hline \multirow[b]{2}{*}{ AACI } & Equal variance & \multirow[b]{2}{*}{1.290} & \multirow[b]{2}{*}{0.256} & -6.532 & 498 & 0.000 & -1.937 \\
\hline & $\begin{array}{l}\text { Unequ. } \\
\text { Variance }\end{array}$ & & & -6.529 & 498 & 0.000 & -1.937 \\
\hline \multirow[b]{2}{*}{ CGAF } & Equal variance & \multirow[b]{2}{*}{0.354} & \multirow[b]{2}{*}{0.552} & -5.151 & 498 & 0.000 & -1.100 \\
\hline & $\begin{array}{c}\text { Unequ. } \\
\text { Variance }\end{array}$ & & & -5.435 & 498 & 0.000 & -1.100 \\
\hline \multirow{2}{*}{ LOSC } & $\begin{array}{c}\text { Equal } \\
\text { Variance }\end{array}$ & \multirow{2}{*}{0.288} & \multirow{2}{*}{0.598} & -1.417 & 498 & 0.157 & -0.228 \\
\hline & $\begin{array}{c}\text { Unequ. } \\
\text { Variance }\end{array}$ & & & -1.417 & 498 & 0.157 & -0.228 \\
\hline \multirow{2}{*}{$\mathrm{SOC}$} & $\begin{array}{c}\text { Equal } \\
\text { Variance }\end{array}$ & \multirow{2}{*}{0.245} & \multirow{2}{*}{0.621} & -5.473 & 498 & 0.000 & -0.955 \\
\hline & $\begin{array}{c}\text { Unequ. } \\
\text { Variance }\end{array}$ & & & -5.435 & 498 & 0.000 & -0.955 \\
\hline \multirow{2}{*}{$\mathrm{TT}$} & $\begin{array}{c}\text { Equal } \\
\text { Variance }\end{array}$ & \multirow{2}{*}{0.000} & \multirow{2}{*}{0.999} & -1.413 & 498 & 0.158 & -0.120 \\
\hline & $\begin{array}{c}\text { Unequ. } \\
\text { Variance }\end{array}$ & & & -1.413 & 498 & 0.158 & -0.120 \\
\hline
\end{tabular}

The two-factor t-test results show that the corresponding $\mathrm{P}$ value is greater than 0.1 and it is not significant in the $10 \%$ significance level. It shows that there are no differences between the two factors in the flow experience of college students in different skills sports in terms of "lack of selfconsciousness" and "time shift". And for the other four factors, there are significant differences in "self-contained experience", "integration of action and consciousness", "clear goal and feedback", and "sense of control".

\section{Differences of Flow Experience among Different Years of College Students}

The total score of flow experience is ranked as freshmen (128.308), senior (124.108), junior (117.893), and sophomore (117.834). The total score of freshmen and seniors are significantly higher than that of sophomores and juniors. Table 15 shows details of the comparison. 
Table 15. Mean and Standard Deviation of the Flow Experience of College Students of Different Years

\begin{tabular}{cccc}
\hline Grade & Observation & Mean & Standard Error \\
\hline Freshmen & 168 & 128.308 & 20.188 \\
Sophomore & 122 & 117.834 & 16.536 \\
Junior & 114 & 117.893 & 17.923 \\
Senior & 96 & 124.108 & 18.520 \\
Total & 500 & 121.101 & 18.549 \\
\hline
\end{tabular}

Table 16. Multiple Comparisons of Flow Experience of College Students of Different Years

\begin{tabular}{ccccc}
\hline (I) Grade & $(\mathrm{J})$ Grade & $(\mathrm{I}-\mathrm{J})$ & Standard Error & Significance \\
\hline \multirow{3}{*}{ Freshmen } & Sophomore & $10.474^{*}$ & 4.994 & 0.035 \\
& Junior & $10.415^{*}$ & 4.924 & 0.033 \\
& Senior & $4.200^{*}$ & 4.853 & 0.041 \\
\hline \multirow{3}{*}{ Sophomore } & Freshmen & $-10.474^{*}$ & 4.994 & 0.035 \\
& Junior & -0.059 & 1.365 & 0.943 \\
& Senior & $-6.274^{*}$ & 3.532 & 0.037 \\
\hline \multirow{3}{*}{ Junior } & Freshmen & -10.415 & 4.924 & 0.033 \\
& Sophomore & 0.059 & 1.365 & 0.943 \\
& Senior & -6.215 & 3.486 & 0.039 \\
\hline \multirow{2}{*}{ Senior } & Freshmen & $-4.200^{*}$ & 4.853 & 0.041 \\
& Sophomore & $6.274^{*}$ & 3.532 & 0.037 \\
& Junior & $6.215^{*}$ & 3.486 & 0.039 \\
\hline
\end{tabular}

Note: * denotes significant at $5 \%$ significance level

In Table 16, it can be seen that the total score of freshmen and seniors are significantly higher than that of sophomores and freshmen. Table 17 shows the average and standard deviation of flow experience of students of different years in sports. It can be seen that there is a difference between "freshmen, juniors" and "sophomores, juniors" in flow experience. However, the difference is manifested in "self-contained experience" and "lack of selfconsciousness".

Table 17. Mean and Standard Deviations of Flow Characteristics of College Students of Different Years

\begin{tabular}{cccccc}
\hline Factors & Freshmen & Sophomore & Junior & Senior & Whole \\
\hline SCE & $36.385 \pm 5.924$ & $33.025 \pm 5.638$ & $32.991 \pm 5.592$ & $32.588 \pm 5.638$ & $32.900 \pm 5.629$ \\
\hline AACI & $31.461 \pm 5.532$ & $28.950 \pm 5.060$ & $29.211 \pm 5.178$ & $29.020 \pm 5.239$ & $29.191 \pm 5.179$ \\
\hline CGAF & $21.769 \pm 4.781$ & $21.225 \pm 3.556$ & $21.060 \pm 3.745$ & $20.808 \pm 3.706$ & $21.017 \pm 3.706$ \\
\hline LOSC & $14.539 \pm 3.479$ & $12.146 \pm 2.665$ & $12.250 \pm 2.827$ & $13.030 \pm 2.598$ & $12.516 \pm 2.759$ \\
\hline SOC & $16.846 \pm 2.853$ & $15.446 \pm 2.891$ & $15.344 \pm 3.116$ & $15.540 \pm 3.003$ & $15.447 \pm 3.032$ \\
\hline TT & $7.308 \pm 1.182$ & $7.092 \pm 1.443$ & $7.087 \pm 1.432$ & $7.121 \pm 1.521$ & $7.102 \pm 1.461$ \\
\hline
\end{tabular}

\section{Conclusion}

Based on the flow experience theory, this paper carries out an empirical analysis of the characteristics of the flow experience of college students in Shanghai, including three aspects of the flow experience characteristics, the difference of flow experience in different skill types sports, and the difference in the flow experience characteristics of students in different 
years. This paper contributes to existing literature on positive psychology in sports. Besides, it can help better promote college students' active participation in sports and physical and mental health in Shanghai. The questionnaire is based on the "flow state scale" of Jackson and Marsh (1994). After a preliminary test, 500 questionnaires were handed out. Factor analysis shows that the flow experience characteristics of college students in Shanghai includes 6 factors: self-contained experience, action and consciousness integration, clear goal and feedback, lack of sense of control, and time transformation. There are differences in the characteristics of flow experience in different skill sports. The flow experience in closed motor skill sports is higher than the flow experience in open motor skill sports. The main differences are reflected in four factors, which include self-consciousness, action and consciousness integration, clear goals and feedback, and sense of control. There is also a significant difference in flow experience among college students at different years. There is no significant difference in the flow experience of the sophomores and senior students in sports, while freshmen and senior students have a higher level of flow experience in sports than students in the other two years.

Based on empirical results, it can be concluded that active participation in sports can better serve students' physical and mental health and help them deal with the challenges of life. Also, it would help them to be more optimistic and healthy. Meanwhile, the flow experience can help them integrate into social work faster and more active work in the future. The following policy implications are proposed.

Firstly, colleges are encouraged to improve sports infrastructure, especially facilities for closed motor skills sports facilities. With the implementation of the concept of the national sports movement and the longing for active life attitudes, the idea of college students' fitness exercise has also become stronger. Besides, college students are eager to put the idea of life-long exercise into practice. However, problems such as inadequate facilities on university campus and high fees for off-campus gymnasiums often become obstacles for students to exercise, so that they cannot get a better flow experience and even give up the idea of exercising. Therefore, as an institution of higher learning, it is necessary to appropriately increase the investment in the construction of sports venues and facilities on campus after understanding students' intentions for body-building exercises. Also, it is important to promote the use of these facilities in schools through multiple channels. At the same time, this paper stated that college students have a better flow experience in closed motor skill sports. Therefore, universities should regard closed motor skills sports related facilities as their main investment targets. 
Secondly, colleges are encouraged to adjust curriculum and pay more attention to the flow of sports experience and develop students' attention in the exercising process. This paper shows that sophomores and juniors have poorer flow experiences than freshmen and seniors, which are mainly reflected in "self-contained experience" and "lack of self-consciousness". Compared to freshmen and senior students, there are relatively more courses for sophomores and juniors, which are also more difficult to complete. Students have less energy to devote themselves to sports and are less able to participate in physical activities. Therefore, this paper proposes that colleges should adjust the setting of the curriculum, pay attention to students' sports concentration, and thus enhance their flow experience and promote the positive development of spirit and body.

\section{References:}

1. Horn, T. 1992, Frontiers of Sports Psychology, Beijing Sport University Press, Beijing.

2. Hu J. 2008, Satisfaction of College Students in Physical Exercise Class - Evidence frm Flow Experience, Sports and Science (in Chinese), 2008, 08(8).

3. Hu et al. 2002, Comparison of Flow Experience between Chinese and American Elite Female Volleyball Players, Journal of Guangzhou Sport College (in Chinese), 2002, 22(4), Page 42-43.

4. Jackson S.A. and Marsh H.W. 1994, Development and Validation of a Scale to Measure Optimal Experience: The Flow State Scale, Sport and Exercise Psychology, 1996, 18 (1), Page 17-35.

5. Jiang M, and Sun Y. 2001, The Relationship between Flow Experience and Performance - Evidence from Elite Female Volleyball Players, China Sport Technology (in Chinese), 2001, 37(6), Page 14-18.

6. Liang, D.Q. 1994, The Stress Level of College Students and their Relationship with Physical Exercise, Chinese Mental Health Journal (in Chinese), 1994, 01(5), Page 5-6.

7. Li S. and Sun Y. 2000, Flow Experience of Basket Ball Players, Sports and Science (in Chinese), 21(3), Page 40-43.

8. Liu, S. 2008, Inducement and Controllability of Flow Experience of Elite Tennis Players, Journal of Shanghai Sport University (in Chinese), 32(3), Page 58-60.

9. Liu, W. and Ji, L. 2009, Research Progress in Flow Experience in Sports, Sports Science (in Chinese), Page 72-78.

10. Privette G. and Bundrick C.M. 1987, Measurement of Experience: Construct and Content Validity of the Experience Questionnaire. Perceptual and Motor Skills, 65, Page 315-332. 
11. Ren J., Shi J and Ma T.Y. 2009, A Summary of Researches on Flow, Progress in Psychological Science (in Chinese), 2009, 17(1), Page 210217.

12. Xu, X. 2007, Review of Flow, West China Technology, 2007, 08, Page 54-56.

13. Xu, X. and Wang J. 2006, Exploration of Flow in Physical Exercises, Zhejiang Sports Science (in Chinese), 28(6), Page 41-45.

14. Zhou, H. 2008, Investigation of College Students' Flow Experience in Sports, Zhejiang Sports Science (in Chinese), 2008, 09(5), Page 66-69.

\section{Appendix}

A Questionnaire on the Sports Research of College Students in Shanghai

Thank you for taking part in this questionnaire survey! The questionnaire will not be used for commercial purposes. The questionnaire is suitable for college students in all colleges and universities in Shanghai. The test intensity of the scale is 5 subscales. "1" means "strong disagreement", " 2 " is "disagreement", "3" means "do not know", "4" means "agreement", and "5" means "strong agreement".

1. Which College Do You Attend?

2. What is Your Gender? [Male; Female]

3. Which Year Are You in? [Freshmen; Sophomore; Junior; Senior]

4. Sports You Often Participate in? [Football; Basketball; Badminton; Table Tennis; Volleyball Tennis; Aerobics; Yoga; Running; Swimming; Fitness; None; Not in the List (Please Specify). 


\begin{tabular}{|c|c|c|}
\hline $\begin{array}{c}\text { Variabl } \\
\text { es }\end{array}$ & Questions & $\begin{array}{c}\text { Scor } \\
\mathrm{e}\end{array}$ \\
\hline V1 & $\begin{array}{c}\text { I was challenged, but I believed my skills would allow me to meet the } \\
\text { challenge. }\end{array}$ & $1-5$ \\
\hline $\mathrm{V} 2$ & I made the correct movement without thinking about trying to do so. & $1-5$ \\
\hline V3 & I knew clearly what I wanted to do. & $1-5$ \\
\hline V4 & It was really clear to me that I was doing well. & $1-5$ \\
\hline V5 & My attention was focused entirely on what I was doing. & $1-5$ \\
\hline V6 & I felt in total control of what I was doing. & $1-5$ \\
\hline V7 & I was not concerned with what others may have been thinking of me. & $1-5$ \\
\hline V8 & Time seemed to alter (either slowed down or speeded up) & $1-5$ \\
\hline V9 & I really enjoyed the experience. & $1-5$ \\
\hline V10 & My abilities matched the high challenge of the situation. & $1-5$ \\
\hline V11 & Things just seemed to be happening automatically. & $1-5$ \\
\hline V12 & I had a strong sense of what I wanted to do. & $1-5$ \\
\hline V13 & I was aware of how well I was performing. & $1-5$ \\
\hline V14 & It was no effort to keep my mind on what was happening. & $1-5$ \\
\hline V15 & I felt like I could control what I was doing. & $1-5$ \\
\hline V16 & I was not worried about my performance during the event. & $1-5$ \\
\hline V17 & The way time passed seemed to be different from normal. & $1-5$ \\
\hline V18 & I loved the feeling of that performance and want to capture it again. & $1-5$ \\
\hline 9 & $\begin{array}{l}\text { I felt I was competent enough to meet the high demands of the } \\
\text { situation. }\end{array}$ & $1-5$ \\
\hline V20 & I performed automatically. & $1-5$ \\
\hline V21 & I knew what I wanted to achieve. & $1-5$ \\
\hline V22 & I had a good idea while I was performing about how well I was doing. & $1-5$ \\
\hline $\mathrm{V} 23$ & I had total concentration. & $1-5$ \\
\hline V24 & I had a feeling of total control. & $1-5$ \\
\hline $\mathrm{V} 25$ & I was not concerned with how I was presenting myself. & $1-5$ \\
\hline V26 & It felt like time stopped while I was performing. & $1-5$ \\
\hline V27 & The experience left me feeling great. & $1-5$ \\
\hline V28 & The challenge and my skills were at an equally high level. & $1-5$ \\
\hline V29 & I did things spontaneously and automatically without having to think. & $1-5$ \\
\hline V30 & My goals were clearly defined. & $1-5$ \\
\hline V31 & I could tell by the way I was performing how well I was doing. & $1-5$ \\
\hline V32 & I was completely focused on the task at hand. & $1-5$ \\
\hline V33 & I felt in total control of my body. & $1-5$ \\
\hline V34 & I was not worried about what others may hava been thinking of $m$ & $1-5$ \\
\hline V35 & At times, it almost seemed like things were happening in slow motion. & $1-5$ \\
\hline V36 & I found the experience extremely rewarding. & $1-5$ \\
\hline
\end{tabular}

